\title{
Research on Variable Universe Fuzzy PID Control Strategy of Pipe Lining Induction Heating System
}

\author{
Yuzhong Wang $\mathbb{D}^{\mathbb{D}}$, Min Wei ${ }^{\mathbb{D}}$, Xue Hu, Minghong Jiang, and Lixin Zhang \\ Mechanical and Electrical Engineering College, Shihezi University, Shihezi 832000, China \\ Correspondence should be addressed to Min Wei; 1448237074@qq.com
}

Received 25 August 2020; Revised 16 November 2020; Accepted 25 November 2020; Published 3 December 2020

Academic Editor: Dariusz J. Gawin

Copyright ( 2020 Yuzhong Wang et al. This is an open access article distributed under the Creative Commons Attribution License, which permits unrestricted use, distribution, and reproduction in any medium, provided the original work is properly cited.

\begin{abstract}
It is a promising heat supply strategy to use induction heating for the pipe lining process, but temperature control is hindering its application. In this study, we designed the variable universe fuzzy PID controller, and the lining induction heating system model was used to verify its performance. First, the transfer function parameters of the lining induction heating system are obtained by the step response method. Then, a point-by-point convergent interpolator is established through the contraction-expansion factors to realize the adaptive expansion of the fuzzy universe. Finally, the performance of PID, fuzzy PID, and variable universe fuzzy PID are compared through simulation experiments, and the ability of the controller to resist disturbance is verified by adding interference. The results show that the variable universe fuzzy PID controller can greatly improve the performance of fuzzy PID in response speed and settle time. The average stability error is smaller than PID and fuzzy PID control. It can meet the speed and accuracy requirements of the lining induction heating system. This research can be used as a reference for induction heating precise control and evidence that the variable universe fuzzy PID control can satisfy the lining induction heating process.
\end{abstract}

\section{Introduction}

As a clean and efficient heat supply strategy, the application of an induction heating system in the lining process is limited due to its strict requirements for the temperature control system. The lining process is shown in the Figure 1. The curing temperature directly affects the melting rate of the lining material and the quality of the lining. If the temperature introduced into the lining layer is too high, the thickness of the lining layer will increase, and if it is too low, the thickness of the lining layer will not reach the designed thickness, and temperature oscillation will cause uneven thickness of the lining layer. The induction heating temperature control strategy applied to the lining has more stringent requirements.

In the lining process, lining material should be heated to the melting temperature, but it can withstand a small temperature overshoot range. In fact, for nonmetallic lining materials, the acceptable temperature range is usually $150^{\circ} \mathrm{C}$ to $315^{\circ} \mathrm{C}$ [1]. In general, for polyolefin materials, the engineering requirement is to keep the temperature at $220 \pm 20^{\circ} \mathrm{C}$. In other words, overshoot cannot exceed $9 \%$. It means more precise temperature control to ensure the effectiveness of the lining process. PID control shows a decent performance in accuracy $[2,3]$, but the lining process does not allow longterm large overshoot and temperature oscillation, which may easily lead to failure of the lining layer or nonuniform thickness. Moreover, the induction heating temperature changes extremely fast, which also puts forward a test for the response speed of the control system. It determines that the lack of intelligence PID control is difficult to apply in the lining induction heating system. In recent years, it is based on model prediction $[4,5]$ and the intelligent adjustment method based on PID has good control effects, solving this problem, but predictive control requires a large number of samples to ensure accuracy, which is difficult. In fact, as a method of intelligent tuning PID parameters, fuzzy control is efficient. With the advance of intelligent algorithm research, advanced control methods such as genetic algorithms, neural networks, and gray fuzzy [6-9] are gradually applied to induction heating. Actually, the response speed and overshoot are optimized to a certain extent by fuzzy PID control [10-13]. However, these control strategies add 


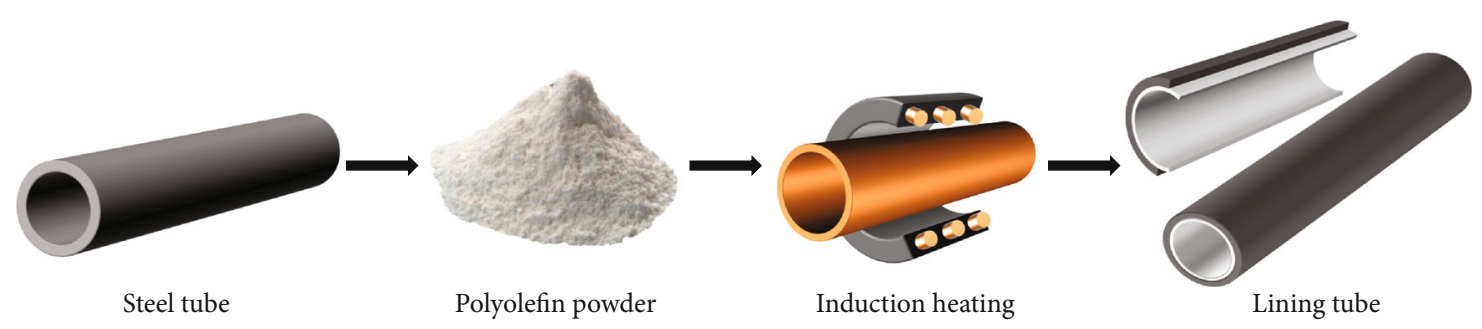

Figure 1: Pipeline lining process sheet. The principle is to fill the polyolefin into the pipe and then heat and solidify it on the inner surface.

an intelligent analysis system with a considerable amount of calculation before the PID controller or fuzzy PID controller directly; it means the feasibility of applying these control strategies to the lining induction heating system is questionable, because the temperature of the lining induction heating system changes quickly, and the lining powder is sensitive to temperature overshoot and accuracy. A large number of analysis calculations before an adjustment and strong oscillation near the steady state will directly affect the uniformity of the lining layer. In addition, it is worth mentioning that on the basis of fuzzy PID control, Professor Arya proposed a series of new controllers for the power system [11, 14-16]. Unfortunately, these controllers have not been proven to be effective in lining induction heating systems. Judging from the research on induction heating in recent years, there are few pieces of research on the temperature control problems applied to lining induction heating. Therefore, it is necessary to explore a controller with a smaller calculation amount and more precise control to improve the adjustment accuracy of the control system, reduce the calculation time, and decrease the overshoot to ensure the uniformity of the lining temperature, thereby ensuring the uniform thickness of the pipe lining layer.

This paper focuses on the temperature control method of the pipe lining induction heating system, in particular, it tends to the adaptive capacity in response speed and overshoot. The paper presents parameter identification of transfer function and detailed design process of variable universe fuzzy PID controller developed to adapt to the rapidity of the induction heating system and temperature accuracy of pipe lining process. The results were used to establish test procedures to simulate the performance of the control process. Simulated tests were performed on the first-order plus dead-time model with step disturbance, in accordance with the analytical model. This paper presents the results of the laboratory tests and properties of the variable universe fuzzy PID controller to provide a new control scheme for the temperature control of the lining induction heating system.

\section{Lining Induction Heating System Model}

2.1. Establish the Transfer Function of the Controlled Object. To design an accurate and high-quality regulator, it is necessary to understand the mathematical model of the controlled object. When the workpiece is placed in a heater with alternating current, it can be noted from the law of electromagnetic induction that an alternating magnetic field can produce an electric field, so an induced electromotive force will be generated inside the workpiece, and a closed-loop can be formed inside the workpiece everywhere. It produces a lower voltage and a larger current, which is an eddy current, which causes a large amount of Joule heat. However, due to the skin effect, the material heated by induction is concentrated on the surface of the penetrating layer, and the depth of penetrating $\delta$ can be expressed as Equation (1)). It reveals that even if the depth of current penetration can be increased by adjusting frequency, it is far from reaching the thickness of a general pipe.

$$
\delta=503 \sqrt{\frac{2 \rho}{2 \pi f \mu_{0} \mu_{r}}},
$$

where $\rho$ is specific resistance, $\Omega \mathrm{m} ; f$ is the frequency of current, $\mathrm{Hz} ; \mu_{0}$ is the permeability of vacuum, $\mathrm{Hm}$; and $\mu_{r}$ is relative permeability. Actually, the material that exceeds the depth reaches the target temperature through a temperature gradient $[17,18]$. Thus, the system model can be simplified power, induction heater, electromagnetic induction heating, and heat conduction to get the open-loop transfer function of the system, as the diagram in Figure 2. Reference [19] has settled the transfer function of the induction heating system.

$$
G(s)=\frac{y(s)}{u(s)}=\frac{K e^{-\tau s}}{T s+1},
$$

where $G(s)$ is the Laplace form of the transfer function model, $y(s)$ and $u(s)$ is the Laplace transformed form of input $Y(t)$ and output and $U(t), K$ is the gain, $T$ is the time constant, and $\tau$ is the dead time.

2.2. Parameter Identification of Transfer Function. The parameters of the transfer function are determined by the step response method [20], because of its simple physical interpretation, which is a convenient way to characterize process dynamics through recording the step response $s(t)$. Put the pipe in the spiral induction heater, set target temperature $220^{\circ} \mathrm{C}$, the current frequency $f=8 \mathrm{kHz}$, the current is $I_{0}=$ $500 \mathrm{~A}$, make the voltage change in steps of $100 \mathrm{~V}$. Equation (2) gives a first-order-plus-dead-time (FOPDT) model; the time constant $T$ reflects response speed. The larger the $T$, the slower the response speed and the longer the rise time. $K$ can be obtained from the steady-state level of the process output, and its identification algorithm can be expressed as

$$
K=\frac{y(\infty)-y(0)}{\Delta U}
$$




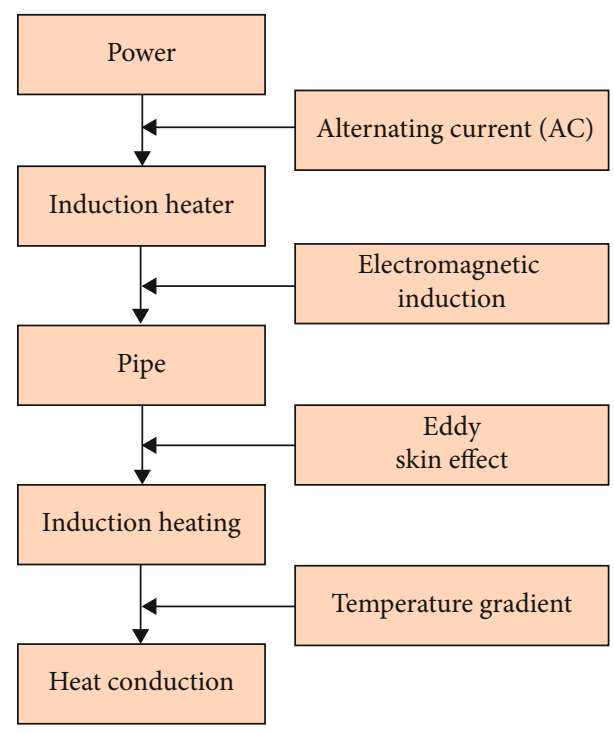

FIgURE 2: Simplified diagram of lining induction heating system.

where $y(\infty)$ represents the steady-state value of the step response, and $y(0)=25$ is the initial value of the system.

As shown in Figure 3, the parameters in Equation (2) can be determined graphically. The static gain $K$ is obtained from the final steady-state level of the process output. The intercept of the tangent to the step response that has the largest slope with the horizontal axes gives $\tau$. One method determines $T$ from the distance AC in Figure 3, where point $C$ is the time when the tangent intersects the line $s(t)=K$. The distance $A B$ is used to be another method to determine $T$, where $B$ is the time when the step response has reached the value $0.63 \mathrm{~K}$ [21]. The latter gives a more reliable approximation.

From the step response diagram, the static gain $K$ is determined to be $4.2, T$ is 285 , and the dead time is $110 \mathrm{~s}$. The following model is obtained.

$$
G(s)=\frac{4.2}{285 s+1} e^{-110 s}
$$

\section{Variable Universe Fuzzy PID Controller Design}

3.1. Variable Universe Fuzzy PID Control. Fuzzy control is primarily used in the closed-loop control of nonlinear systems. Input is fitted by monitoring the state of the output terminal [22], and the adjustment is based on the established control rules. The control accuracy highly depends on the number of fuzzy rules, which make the control process have predictable errors. Based on the fuzzy PID, this paper designs the variable universe fuzzy PID (VUFPID) controller to realize the control of the induction heating system for pipe lining.

For classic PID control, when the input and output change greatly, only a part of the control rules work, which will lead to a decrease in control accuracy. When the domain of the universe is small, the adjustment range of the input and output may exceed it; this will cause the steady-state error to increase when the error is small. The purpose of changing the universe is to inherit the rapidity of fuzzy PID control and to deal with the sudden change of temperature in the induction heating process, optimize control accuracy, and reduce system oscillation to ensure that the lining layer is effective and uniform. Here, through the contractionexpansion factors $\alpha(e), \alpha(e c), \beta\left(K_{p}\right), \beta\left(K_{i}\right)$, and $\beta\left(K_{d}\right)$ to set up a point-by-point convergent interpolator, it can increase the effectiveness of fuzzy rules without changing them. That is, current universes are redefined constantly, which makes the fuzzy rules involved in the adjustment increase relatively. It can be seen from Figure 4 , the performance of VUFPID control depends highly on the contraction-expansion factors, which makes a flexible universe.

As Figure 4 shows, $\alpha(e)$ and $\alpha(e c)$ are the contractionexpansion factors of the input variables, $\beta\left(K_{p}\right), \beta\left(K_{i}\right)$, and $\beta\left(K_{d}\right)$ are the contraction-expansion factors of the output variables of the fuzzy controller, respectively.

3.2. The Contraction-Expansion Factor of Fuzzy Universe. The most direct purpose of control is $\lim _{t \rightarrow \infty}\|e(t)\|=0$. The contraction-expansion factor determines the ability of the controller to adjust to the control object and directly affects the control effect of the VUFPID controller. The initial universe of input variables $e$ and $e c$ are $X=[-E, E]$; output $K_{p}, K_{i}$, and $K_{d}$ are $Y=[-U, U]$; this paper adopts the contraction-expansion factor based on the function model [22].

$$
\begin{aligned}
& \alpha(x)=1-\lambda e^{-k x^{2}}, \\
& \beta(t)=K_{I} \sum_{i=1}^{n} p_{i} \int_{0}^{t} e_{i}(\tau) d \tau+\beta(0),
\end{aligned}
$$

where $0<\lambda<1, k>0$, the size of $k$ value reflects the change speed of the controller's universe. $\lambda$ reflects the control precision of the system. $K_{I}$ is a constant. $\beta(0)$ is the initial value. The transformed universe of input variables can be expressed as

$$
\begin{aligned}
X(e) & =[-\alpha(x) E, \alpha(x) E], \\
X(e c) & =[-\alpha(x) E C, \alpha(x) E C],
\end{aligned}
$$

If $\lambda=0.6$ and $K=0.5$, the contraction-expansion factor of the input variables are

$$
\begin{gathered}
\alpha(e)=1-0.4 e^{-0.5 e^{2}}, \\
\alpha(e c)=1-0.4 e^{-0.5 e c^{2}} .
\end{gathered}
$$

The change of the output variable ratio and the differential coefficient $K_{p}, K_{d}$ should be monotonously consistent with the change of the system deviation, and the integral 


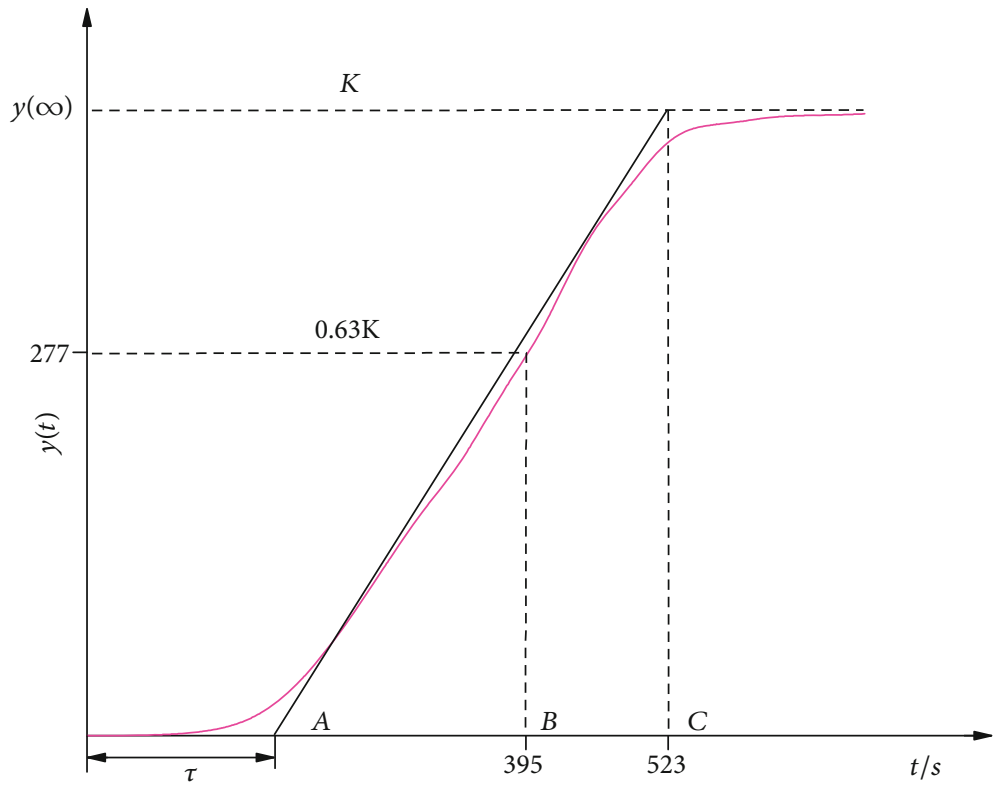

Figure 3: System step response. The distance $A B$ is defined as the system time constant $T$, and $\tau$ is dead time.

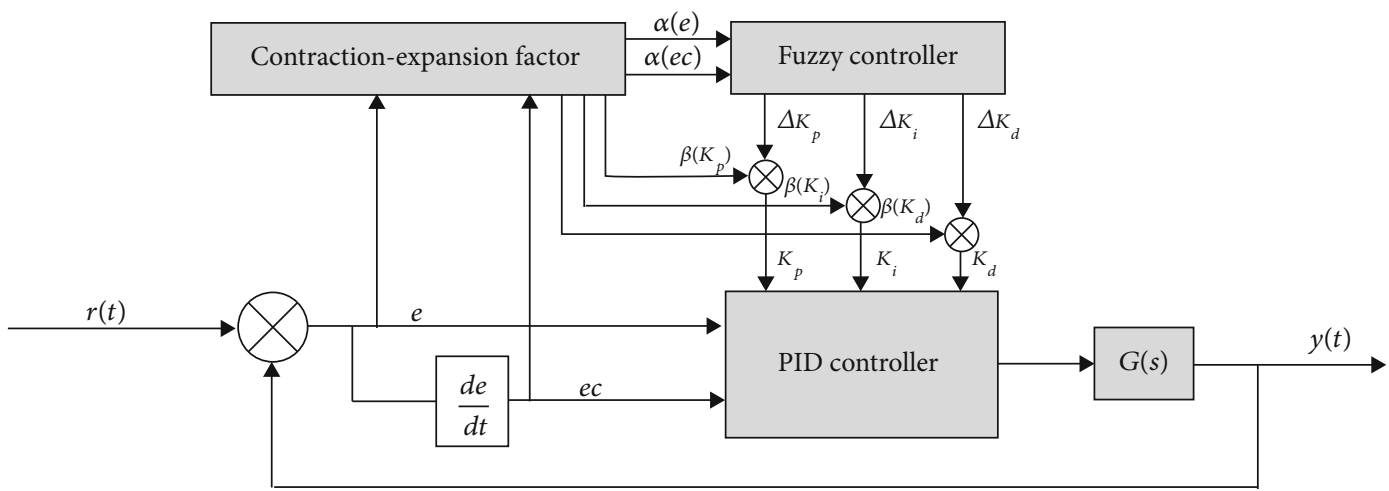

FIGURE 4: VUFPID controller structure diagram; $e, e c$ are the error and its rate of change, respectively, the contraction-expansion factors of inputs and outputs are defined as $\alpha(e), \alpha(e c), \beta\left(K_{p}\right), \beta\left(K_{i}\right)$, and $\beta\left(K_{d}\right)$.

coefficient $K_{i}$ should be monotonic opposite to the system deviation. Here, we choose a more general function form.

$$
\begin{aligned}
& \beta\left(K_{p}\right)=6|e|, \\
& \beta\left(K_{i}\right)=\frac{1}{|e|+0.7}, \\
& \beta\left(K_{d}\right)=6|e| .
\end{aligned}
$$

The output variable universe after transformation can be expressed as

$$
\begin{aligned}
Y\left(K_{p}\right) & =\left[-\beta\left(K_{p}\right) K_{p}, \beta\left(K_{p}\right) K_{p}\right], \\
Y\left(K_{i}\right) & =\left[-\beta\left(K_{i}\right) K_{i}, \beta\left(K_{i}\right) K_{i}\right], \\
Y\left(K_{d}\right) & =\left[-\beta\left(K_{d}\right) K_{d}, \beta\left(K_{d}\right) K_{d}\right] .
\end{aligned}
$$

Here, defining $\mathscr{F}(\cdot)$ as the fuzzy adjustment relationship, the output of fuzzy controller is

$$
\begin{aligned}
\Delta K_{p} & =\mathscr{F}\left(\beta\left(K_{p}\right) \mathscr{F}(\alpha(x) E, \alpha(x) E C)\right), \\
\Delta K_{i} & =\mathscr{F}\left(\beta\left(K_{i}\right) \mathscr{F}(\alpha(x) E, \alpha(x) E C)\right), \\
\Delta K_{d} & =\mathscr{F}\left(\beta\left(K_{d}\right) \mathscr{F}(\alpha(x) E, \alpha(x) E C)\right) .
\end{aligned}
$$

Then, define the initial value of $K_{p}, K_{i}$, and $K_{d}$ as $K_{p 0}$, $K_{i 0}$, and $K_{d 0}$.

At this point, we can uniquely determine the output expression:

$$
\begin{aligned}
u(k)= & \left(\Delta K_{p}+K_{p 0}\right) e(k)+\left(\Delta K_{i}+K_{i 0}\right) \sum_{k=0}^{t} e(k) d k \\
& +\left(\Delta K_{d}+K_{d 0}\right) \frac{d e(k)}{d k} .
\end{aligned}
$$




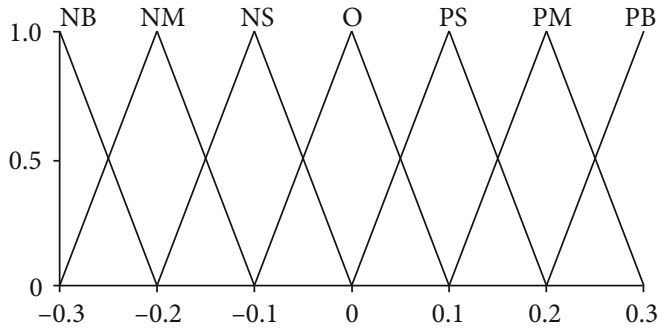

(a)

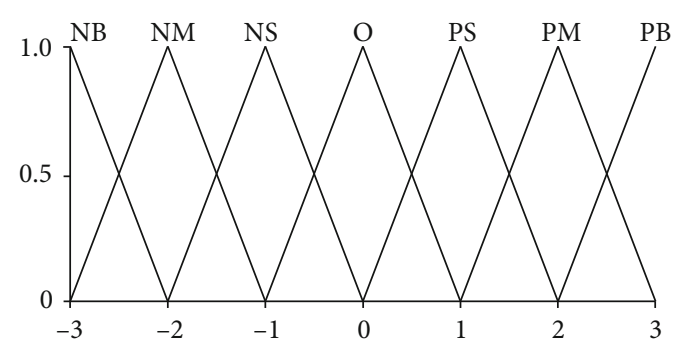

(b)

Figure 5: (a) The membership of $\Delta K_{i}, \Delta K_{d}$. (b) The membership of $e, e c$, and $\Delta K_{p}$.

TABLE 1: Fuzzy rule table.

\begin{tabular}{|c|c|c|c|c|c|c|c|}
\hline \multirow[b]{2}{*}{$e$} & \multicolumn{7}{|c|}{$e c$} \\
\hline & NB & NM & NS & $\mathrm{ZO}$ & PS & PM & PB \\
\hline NB & $\mathrm{NB} / \mathrm{ZO} / \mathrm{PS}$ & $\mathrm{NB} / \mathrm{ZO} / \mathrm{NS}$ & $\mathrm{NB} / \mathrm{ZO} / \mathrm{NB}$ & $\mathrm{NM} / \mathrm{ZO} / \mathrm{NB}$ & $\mathrm{NS} / \mathrm{ZO} / \mathrm{NB}$ & $\mathrm{NS} / \mathrm{ZO} / \mathrm{NM}$ & $\mathrm{ZO} / \mathrm{ZO} / \mathrm{PS}$ \\
\hline NM & NB/NM/PS & NB/NM/NS & NM/NS/NB & NS/NS/NM & NS/NS/NM & $\mathrm{ZO} / \mathrm{ZO} / \mathrm{NS}$ & $\mathrm{PS} / \mathrm{ZO} / \mathrm{ZO}$ \\
\hline NS & $\mathrm{NM} / \mathrm{NB} / \mathrm{ZO}$ & $\mathrm{NM} / \mathrm{NM} / \mathrm{NS}$ & $\mathrm{NM} / \mathrm{NS} / \mathrm{NM}$ & NS/NS/NM & $\mathrm{ZO} / \mathrm{ZO} / \mathrm{NS}$ & PS/PS/NS & $\mathrm{PS} / \mathrm{PS} / \mathrm{ZO}$ \\
\hline $\mathrm{ZO}$ & $\mathrm{NM} / \mathrm{NB} / \mathrm{ZO}$ & $\mathrm{NM} / \mathrm{NM} / \mathrm{NS}$ & NS/NS/NS & $\mathrm{ZO} / \mathrm{ZO} / \mathrm{NS}$ & $\mathrm{PS} / \mathrm{PS} / \mathrm{NS}$ & $\mathrm{PM} / \mathrm{PM} / \mathrm{NS}$ & $\mathrm{PM} / \mathrm{PB} / \mathrm{ZO}$ \\
\hline PS & NS/NS/ZO & NS/NS/ZO & $\mathrm{ZO} / \mathrm{ZO} / \mathrm{ZO}$ & PS/PSIZO & PSIPS/ZO & PMIPMIZO & $\mathrm{PM} / \mathrm{PB} / \mathrm{ZO}$ \\
\hline PM & $\mathrm{NS} / \mathrm{ZO} / \mathrm{PB}$ & $\mathrm{ZO} / \mathrm{ZO} / \mathrm{NS}$ & PS/PS/PS & PM/PS/PS & NM/PS/PS & $\mathrm{PM} / \mathrm{PM} / \mathrm{PS}$ & $\mathrm{PB} / \mathrm{PM} / \mathrm{PB}$ \\
\hline PB & $\mathrm{ZO} / \mathrm{ZO} / \mathrm{PB}$ & PS/ZO/PM & $\mathrm{PM} / \mathrm{ZO} / \mathrm{PM}$ & $\mathrm{PM} / \mathrm{ZO} / \mathrm{PM}$ & $\mathrm{PM} / \mathrm{ZO} / \mathrm{PS}$ & $\mathrm{PB} / \mathrm{ZO} / \mathrm{PS}$ & $\mathrm{PB} / \mathrm{ZO} / \mathrm{PB}$ \\
\hline
\end{tabular}

\subsection{Fuzzy Controller Design}

3.3.1. Selection of Membership Functions for Input and Output Variables. If the surface temperature of the steel tube at time $T$ is set as $t(k)$ and the initial temperature is $t_{0}$, then the error $e(k)=t(k)-t_{0}$ is taken as one input of the fuzzy controller, and the temperature change rate $e c$ is taken as another one. The output variables of the fuzzy controller are the proportional, integral, and differential parameters of the PID controller. Fuzzy subsets of language values of input variables and output variables are defined as \{Negative Big, Negative Small, Zero, Positive Small, Positive Big\}. The universe of error $e$ and error rate of change $e c$ is $X$, and the error size is quantified into seven grades, which are, respectively, expressed as $-3,-2,-1,0,1,2$, and 3 . Then, $X=\{-3,-2,-1$, $1,2,3\}$. The output quantity $U$ is defined as $K_{p}, K_{i}$, and $K_{d}$, and the universe is $Y_{p}, Y_{i}$, and $Y_{d}$. It is also divided into seven grades: $Y_{p}=\{-3,-2,-1,0,1,2,3\}, \quad Y_{i}=\{-0.3,-0.2,-0.1$, $0,0.1,0.2,0.3\}$, and $Y_{d}=\{-0.3,-0.2,-0.1,0,0.1,0.2,0.3\}$. The membership function is shown in Figure 5.

3.3.2. The Establishment of Fuzzy Control Rules. When the deviation value of the system is very generous, no matter how the change rate of the error changes, the controller should be allowed to output the maximum control effect, to quickly decrease the error. Fuzzy language value is defined as $\operatorname{Big}(B)$; when $e \cdot e c>0$, it indicates that the deviation is changing towards increasing its absolute value of error, the controller should output a control smaller than $B$, and the fuzzy language value is defined as Middle Big (MB), similarly, $S$ (Small) and MS (Middle Small) is defined. When the controller needs to maintain the current state, the output will

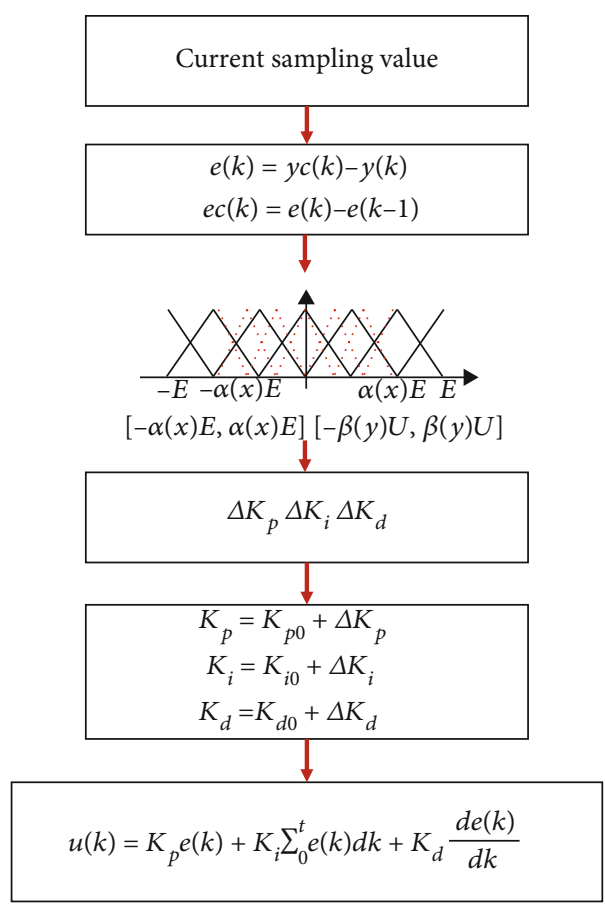

Figure 6: Control logic structure diagram of variable universe fuzzy PID. $y c(k)$ is set as the point value.

not change, and the fuzzy language value at this time is defined as ZO. In order to better define the control interval, $M_{\max }$ is assumed to indicate that the error at the starting stage of the system is far from the set value. The system error can be divided into the following ranges.

$$
e(k)>M_{\max }
$$




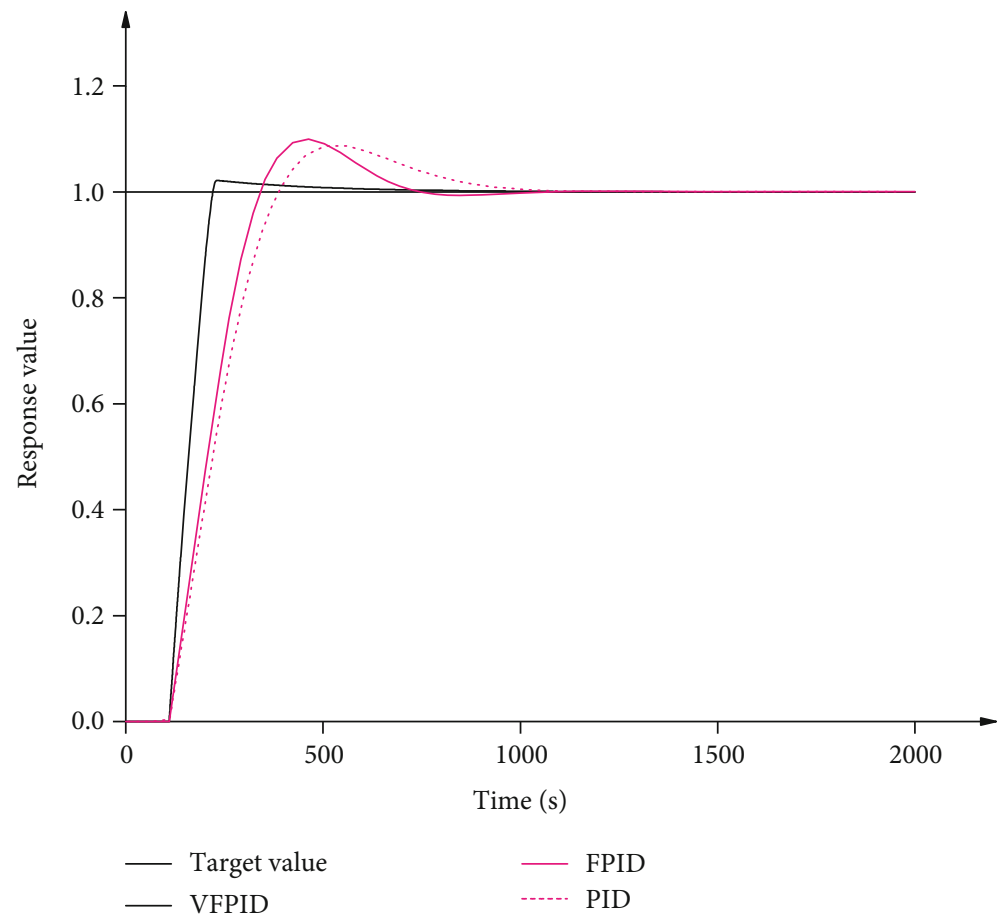

Figure 7: System response curve.

At this time, the influence of the rate of error change on the flux regulation is not considered. No matter how the EC changes, the controller should output the maximum control effect, so as to achieve the purpose of rapidly reducing the deviation.

$$
\text { (1) }|e(k)| \leq M_{\max }, e \cdot e c \leq 0 \text {, or } e c(k) \cdot e c(k-1) \leq 0
$$

In this case, the error changes in the direction in which the absolute value of the error increases or the error remains a fixed value. At this point, if $|e(k)|$ is large, the controller can be made to implement a strong control effect, so that the deviation will change to the direction of its smaller absolute value. In contrast, if $|e(k)|$ is small, but its rate of change is bigger, it can implement the stronger control function, and when the rate of change is small, it can control the implementation of the smaller, namely, despite the error absolute value to change the direction of change, but its absolute value is not big. In order to avoid a larger system overshoot and oscillation, it reduces the control function of the controller and make its slow adjustment to the target value.

(2) $|e(k)| \leq M_{\max }, e \cdot e c \leq 0$, and $e c(k) \cdot e c(k-1) \geq 0$ or $e=0$

It indicates that the deviation changes towards the direction of decreasing its absolute value or has reached an equilibrium state. At this point, when the deviation itself and the rate of change are small, a small control effect can be output; when the deviation is small and the rate of change of deviation is large, a large control effect can be output.

(3) $|e(k)| \leq M_{\max }, e \cdot e c \leq 0$ and $e c(k) \cdot e c(k-1) \leq 0$
TABle 2: Performance parameter comparison.

\begin{tabular}{lccc}
\hline Control type & Rise time $(\mathrm{s})$ & Overshoot $(\%)$ & Settling time $(\mathrm{s})$ \\
\hline PID & 525 & 8.9 & 1070 \\
FPID & 450 & 9.9 & 1020 \\
VUFPID & 230 & 1.5 & 640 \\
\hline
\end{tabular}

At this time, the deviation is in the limit state. If the deviation is large at this time, a strong control effect should be implemented. If the deviation is slight at this point, a weaker control effect should be applied. Based on the above analysis, a fuzzy control rule table for output $K_{p}, K_{i}$, and $K_{d}$ of the fuzzy controller is established, as shown in Table 1.

\section{Simulation and Discussion}

In order to verify the performance of the variable universe FPID controller on the pipe lining induction heating system, the control performance of PID, fuzzy PID, and variable universe fuzzy PID are compared through a simulation test. The operation logic is shown in Figure 6.

The system collects the signal at the current moment in a certain period, and the controller will calculate the error $(e)$ and its rate of change $(e c)$ of the current signal, respectively. Then, the controller changes the fuzzy universe of inputs and outputs based on $e$ and $e c$ through the contractionexpansion factors. In this way, the output of the fuzzy controller $\Delta K_{p}, \Delta K_{i}$, and $\Delta K_{d}$ can be obtained. Then, add the initial values of the three output quantities to obtain the coefficient parameters of the PID controller. At this point, 


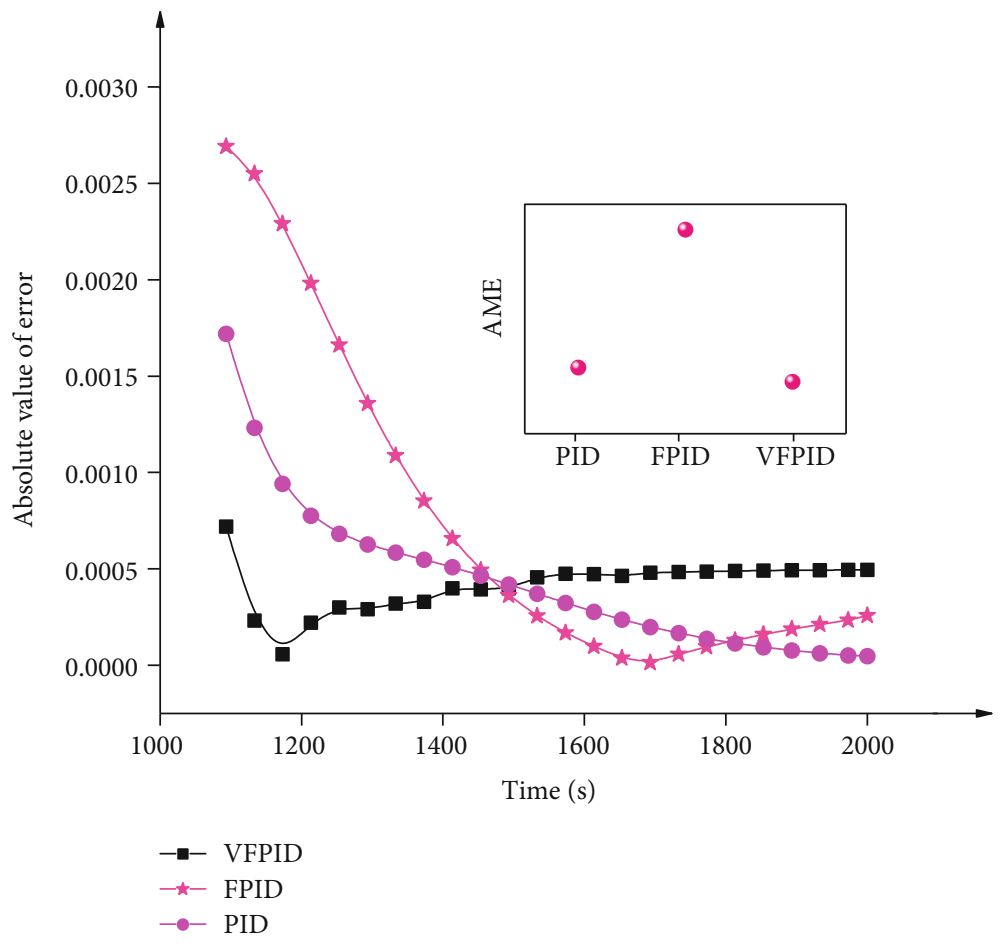

Figure 8: The error absolute value and average magnitude of error (AME) distribution curve.

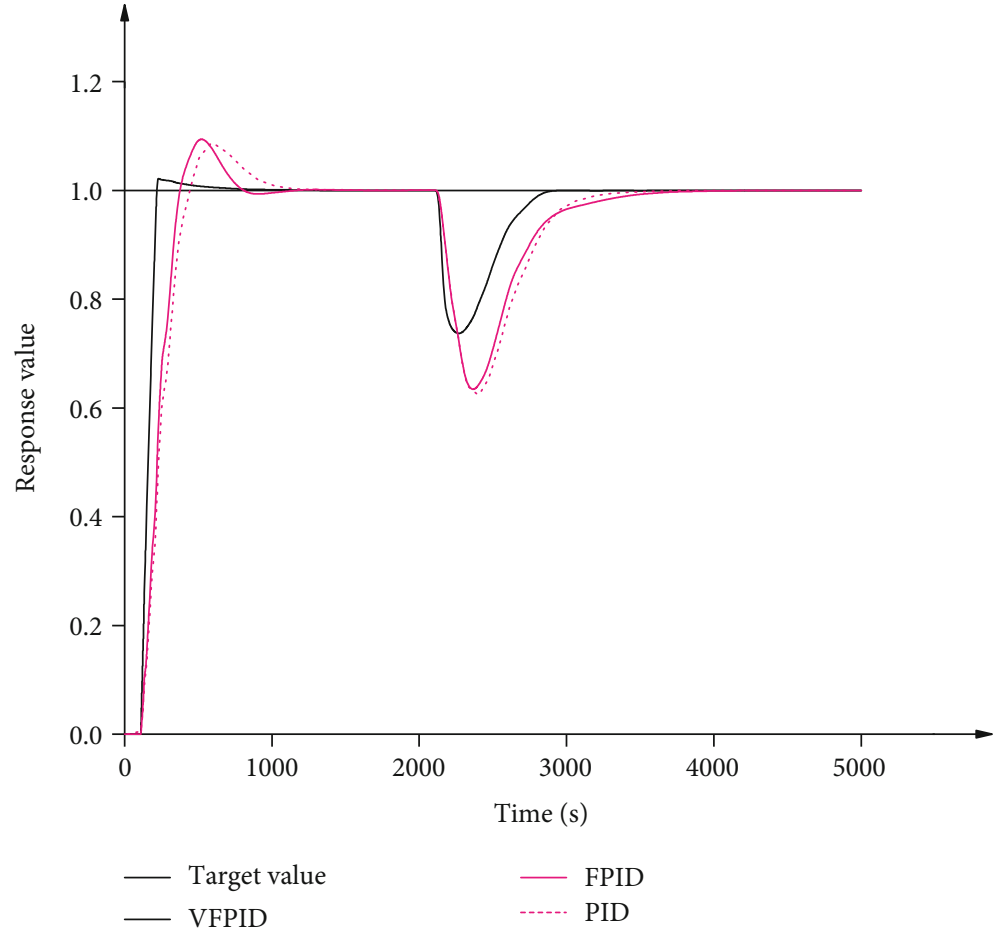

FIGURE 9: Disturbance regulation diagram.

the output at a certain moment will be uniquely determined: $u(k)=K_{p} e(k)+K_{i} \sum^{t} e(k) d k+K_{d}(d(e(k)) / d k)$.

In the simulation test, input the unit step signal, the sampling period is $1 \mathrm{~s}$, the simulation time is $2000 \mathrm{~s}$, the initial values of $K_{p}, K_{i}$, and $K_{d}$ are $0.3,0.001$, and 0.01 , respectively.
The response curve of control system is shown in Figure 7. Dynamic response of these control methods set out in Table 2; it is seen from the table that the maximum overshoot of PID and VUFPID is within 9\%; both of them can be satisfied with the temperature control requirements of lining 
induction heating for polyolefin materials. However, the large overshoot and oscillation when the PID control is close to the target value cannot be tolerated by the lining polymer material. The variable universe fuzzy PID control greatly optimizes the traditional classic control method in overshoot, rise time, and settling time. In detail, compared with PID and fuzzy PID, variable universe fuzzy PID has reduced the rise time by $58 \%$ and $48 \%$, respectively, which can adapt to the rapid temperature change characteristics of induction heating. Compared with the PID control method used in [23], the variable universe fuzzy PID control has a promising performance in the adjustment time. In addition, the overshoot of VUFPID is $1.2 \%$. For instance, when the temperature is set to $220^{\circ} \mathrm{C}$, the temperature fluctuates within $4^{\circ} \mathrm{C}$. For nonmetal lining materials, this temperature range is completely acceptable. Furthermore, the settling time reduced by nearly $40 \%$. It is worth mentioning that, as Figure 8 shows, the steady-state error fluctuation of VUFPID control is small, and its average value is smaller than PID control, which is one of the results of the efficient use of fuzzy rules. Compared with literature $[12,24]$, the accuracy and oscillation problems of traditional fuzzy PID control in induction heating have been better solved.

Furthermore, in order to verify the performance of the VUFPID controller against disturbance signal, step signal disturbance with an amplitude of -0.2 was added at the 2000 s. After 500 seconds of testing, the results are shown in Figure 9. It shows that the maximum amplitude of the variable universe fuzzy PID control is 0.85 , whereas FPID and PID magnitude are about 0.6. In addition, VUFPID recovered to a steady state in $700 \mathrm{~s}$; nevertheless, PID and FPID require more adjustment time. It indicated that the VUFPID control can effectively adjust the oscillation caused by the disturbance and gets a better ability to adapt to the disturbance than the PID and FPID.

Therefore, we have enough evidence to show that the variable universe fuzzy PID control can be applied in the induction heating of lining. It can adapt to the rapid change of induction heating temperature and the high precision of adjustment.

\section{Conclusions}

In this paper, we presented a temperature control method based on variable universe fuzzy PID for a lining induction heating system and indentified the system model through the method of step response. Through the simulation test of the FOPDT model shows, compared with PID and fuzzy PID, the rise time is reduced by $56 \%$ and $48 \%$, respectively, and the overshoot is $2 \%$, that is, the temperature control accuracy is within $4^{\circ} \mathrm{C}$, which can meet the high precision requirements of the lining process. Settling time was reduced by about $40 \%$. In addition, the average steady-state error of theVUFPID control is smaller than PID. Through the research of the temperature control of the lining induction heating system, it is intended as a reference for nonlinear systems with high control performance requirements. It also provides the basis for the application of induction heating in the lining industry.

\section{Data Availability}

Relevant supporting data has been embedded in the paper in the form of charts.

\section{Conflicts of Interest}

The authors declare that there are no conflicts of interest regarding the publication of this article.

\section{Acknowledgments}

This research was supported by the Xinjiang Production and Construction Corps Industrial and High-Tech Science and Technology Breakthrough and Achievement Transformation Project (grant number: 2018GY05) and the Postgraduate Education Innovation Plan of Xinjiang Uygur Autonomous Region (grant number: XJ2020G096).

\section{References}

[1] S. D. Cramer and B. S. Covino, ASM Handbook: Corrosion: Fundamentals, Testing, and Protection, vol. 13, A. ASM international, 2003.

[2] S. Karpushkin and A. Glebov, "Finite-element analysis of induction heating devices during pid-control stage," in 18th International Multidisciplinary Scientific GeoConference SGEM2018, Informatics, Geoinformatics and Remote Sensing, vol. 18, pp. 397-404, Bulgaria, 2018.

[3] W. Xu, J. Zhang, and R. Zhang, "Application of multi-model switching predictive functional control on the temperature system of an electric heating furnace," ISA Transactions, vol. 68, pp. 287-292, 2017.

[4] M. Nawaz, M. A. Saqib, S. A. R. Kashif, and M. Gul, "Constrained model predictive control for an induction heating load," Transactions of the Institute of Measurement and Control, vol. 41, no. 1, pp. 210-218, 2018.

[5] A. Khati, A. Kansab, R. Taleb, and H. Khouidmi, "Current predictive controller for high frequency resonant inverter in induction heating," International Journal of Electrical and Computer Engineering, vol. 10, no. 1, p. 255, 2020.

[6] M. Pirasteh-Moghadam, M. G. Saryazdi, E. Loghman, E. A. Kamali, and F. Bakhtiari-Nejad, "Development of neural fractional order PID controller with emulator," ISA Transactions, 2020.

[7] L. Mei-qiu and Z. Fan, "Application of grey fuzzy PID control in induction heating pipeline," Mechanical \& Electrical Engineering Technology, vol. 48, no. 3, pp. 151-154, 2019.

[8] I. M. Chew, F. Wong, A. Bono, J. Nandong, and K. I. Wong, "Genetic algorithm optimization analysis for temperature control system using cascade control loop model," International Journal of Computing and Digital Systems, vol. 9, no. 1, 2020.

[9] X. B. Li, D. Liu, S. B. Jiao, and J. X. Guo, "Intelligent PID control system for vacuum annealing furnace workpieces temperature," in Proceedings of 2004 International Conference on Machine Learning and Cybernetics (IEEE Cat. No.04EX826), Shanghai, China, 2004.

[10] A. Chakrabarti, A. Chakraborty, and P. K. Sadhu, "A fuzzy self-tuning PID controller with a derivative filter for power control in induction heating systems," Journal of Power Electronics, vol. 17, no. 6, pp. 1577-1586, 2017. 
[11] C.-J. Chang, T.-H. Chiang, and C.-C. Tai, "A modified selftuning fuzzy logic temperature controller for metal induction heating," Review of Scientific Instruments, vol. 91, no. 6, article 064905, 2020.

[12] X. G. Hou and C. L. Wang, "Induction heating furnace temperature control based on the fuzzy PID," Applied Mechanics and Materials, vol. 217-219, pp. 2463-2466, 2012.

[13] N. Teng and J. Zhang, "Vacuum induction heating furnace temperature control system based on Smith fuzzy-PID," in 2014 International Conference on Mechatronics and Control (ICMC), Jinzhou, China, 2015.

[14] Y. Arya, "AGC of PV-thermal and hydro-thermal power systems using CES and a new multi-stage FPIDF-(1+PI) controller," Renewable Energy, vol. 134, pp. 796-806, 2018.

[15] Y. Arya, "Impact of ultra-capacitor on automatic generation control of electric energy systems using an optimal FFOID controller," International Journal of Energy Research, vol. 43, no. 14, 2019.

[16] Y. Arya, "Impact of hydrogen aqua electrolyzer-fuel cell units on automatic generation control of power systems with a new optimal fuzzy TIDF-II controller," Renewable Energy, vol. 139, pp. 468-482, 2019.

[17] J. Davies, "Conduction and induction heating," IET, vol. 24, no. 11, pp. 310-311, 1990.

[18] Q. Yang, Study on induction heating process modeling and temperature control of steel pipe coating crafts, [Ph.D. thesis], Hangzhou Dianzi University, 2017.

[19] N. Teng and J. Zhang, "Vacuum induction heating furnace temperature control system based on Smith fuzzy-PID," in 2014 International Conference on Mechatronics and Control (ICMC), pp. 2207-2210, Jinzhou, China, 2014.

[20] T. Liu and F. Gao, "A frequency domain step response identification method for continuous-time processes with time delay," Journal of Process Control, vol. 20, no. 7, pp. 800-809, 2010.

[21] J. H. Lilly, Fuzzy Control and Identification, John Wiley \& Sons, 2011.

[22] H.-X. Li, Z.-H. Miao, and E. S. Lee, "Variable universe stable adaptive fuzzy control of a nonlinear system," Computers \& Mathematics with Applications, vol. 44, no. 5-6, pp. 799-815, 2002.

[23] A. O. Glebov, S. V. Karpov, S. V. Karpushkin, and E. N. Malygin, "Modeling the induction heating of press equipment in an automatic-temperature-control mode," Journal of Engineering Physics and Thermophysics, vol. 92, no. 5, pp. 11301141, 2019.

[24] C. J. Chang, T. H. Chiang, and C. C. Tai, "A modified selftuning fuzzy logic temperature controller for metal induction heating," Review of Entific Instruments, vol. 91, no. 6, article 064905, 2020. 